\title{
Optimization of the Properties of Electrodeposited Ni-YSZ Composites Using Taguchi Method and Regression Analysis
}

\author{
S.T. Aruna, ${ }^{*}$ P.V.K. Srikanth, M. Jamil Ahamad, S. Latha and K.S. Rajam \\ Surface Engineering Division, Council of Scientific and Industrial Research- \\ National Aerospace Laboratories, Bangalore-560017, India
}

Received 27 April 2009; accepted 28 December 2010

\begin{abstract}
Properties of electrodeposited $\mathrm{Ni}$-composite coatings containing ceramic particles are very much dependant on the bath used, current density, duration of deposition, particle content in the bath, etc. In the present study, the influence of process parameters like the concentration of particles, current density and time of deposition on the area fraction of yttria stabilized zirconia (YSZ), the microhardness and the thickness of the electrodeposited nickel (Ni)-YSZ composite coating was analyzed by Taguchi Design method and analysis of variance (ANOVA). According to the experimental results and ANOVA, the interaction of current and time are the most significant factors influencing the thickness of the coating; interaction of concentration of particles in the electrolyte bath and current are the most significant factors influencing the microhardness; and concentration of particles in the electrolyte bath is the most significant factor affecting the area fraction of particles in the Ni matrix. Models were developed for predicting the microhardness and thickness of the composite coating and area fraction of particles incorporated in the nickel matrix. They were found to be in good agreement with the experimental results. The models were tested for experimental conditions and were found to be close to predicted values. The thickness of the deposit was mainly dependent on the current density and duration of plating. On the other hand, the microhardness of the coating and area fraction of particles present in the nickel matrix were mainly dependent on the amount of particles present in the bath.
\end{abstract}

Keywords: Taguchi method, nickel, YSZ, electrocodeposition, ANOVA, S/N ratio.

\section{Introduction}

In recent years, research and development on metal matrix composite coatings (MMCs) have been gaining importance. These composite coatings possess

\footnotetext{
* Corresponding author. E-mail address: aruna_reddy@nal.res.in
} 
enhanced properties such as wear, corrosion and oxidation resistance, dispersion hardening or self-lubrication relative to pure metal, so that they can protect the metal substrates more effectively against severe environments during operation [1]. MMCs find applications as wear resistant coatings, self-lubricating films and thermal barrier coatings. However, these properties depend on the contributions from the distributed and matrix phases of a composite coating. The MMCs can be produced through a number of routes including metal processing, powder metallurgy, electrodeposition techniques, etc. [2]. MMCs can be prepared by electrodeposition technique by the co-deposition of fine ceramic or polymer particles in a metal matrix from electrolytic baths. Electrodeposition is a lowtemperature process to fabricate nanocomposite coatings in a single step without secondary treatment. Electrodeposited nickel has uniquely high density, minimum porosity and has been widely used in the chemical, mechanical and electronic industries because of its wear and corrosion resistance [3-5]. One of the continuing goals of the nanocomposite coatings is the production of coatings with enhanced properties such as higher microhardness, corrosion resistance and wear resistance. The coatings of this nature are being widely used for surface protection of various metal articles, including internal combustion engine cylinders. There are reports on the incorporation of nanosize $\mathrm{SiC}, \mathrm{ZrO}_{2}, \mathrm{Al}_{2} \mathrm{O}_{3}$, $\mathrm{TiO}_{2}, \mathrm{La}_{2} \mathrm{O}_{3}$ and $\mathrm{CeO}_{2}$ in the nickel matrix forming nanocomposites and their improved corrosion and wear resistances [6-13]. The unique mechanical and electronic properties of zirconia $\left(\mathrm{ZrO}_{2}\right)$ ceramics have led to their widespread use as structural materials, solid-state electrolytes, and thermal barrier coatings. Yttria-fully stabilised zirconia (YSZ) has a unique combination of mechanical properties such as excellent thermal stability, high fracture toughness, Young's modulus and thermal expansion coefficient close to steel [14]. The properties of Ni-YSZ composite depend on the process parameters used for electrodeposition. The content of the particles incorporated depends on different factors related to the particles, such as size, density, composition, zeta potential and conductivity of particles or to the electrolytic solution, such as concentration, $\mathrm{pH}$, temperature, current density and stirring speed.

There are a few reports on the design of experiments for the electrodeposition of Ni-composite coatings. Kuo used Robust design method to study the influence of process parameters on the content of $\mathrm{MoS}_{2}$ in nickel composite coating (Ni$\mathrm{MoS}_{2}$ ) [15]. Ramanathan et al. have studied the volume $\%$ of diamond in $\mathrm{Ni}$ diamond coatings electrodeposited from a Watts bath using sedimentation technique using regression and artificial neural network models [16]. Sahoo and Pal have optimized the tribological performance of electroless $\mathrm{Ni}-\mathrm{P}$ coatings using Taguchi methods [17]. Liu et al. have studied the deposition of nanosized zinc oxide on $\mathrm{Cu}-\mathrm{Zn}$ alloy substrate using Taguchi method [18]. Santana et al. studied electrodeposition of $\mathrm{Ni}-\mathrm{W}-\mathrm{Co}$ amorphous alloys using response surface methodology [19]. To the best of our knowledge there are no reports on the design of experiments and ANOVA on the effect of different processing parameters on the properties (thickness, microhardness and area fraction of particles) of the electrodeposited Ni-YSZ coatings electrodeposited from a nickel sulfamate bath. The aim of this paper was to apply the statistical method for the 
design of experiments to the electrodeposition for the Ni-YSZ and to fit the observed data with suitable models. We have studied the influence of the concentration of YSZ particles, duration of electrodeposition and the applied current density on the area fraction of YSZ particles incorporated in the nickel matrix, microhardness and thickness of the Ni-YSZ coatings using design of experiments and analysis of variance (ANOVA).

\section{Taguchi method}

Taguchi technique is a powerful tool in quality control and optimization of processes. It is a simple and efficient technique which aims at finding the optimum setting of the process control parameters in order to obtain best performance of the process. An efficient way to study simultaneous effects of parameters on the process is by planning experiments using orthogonal array [20]. This method integrates design of experiments with parameter optimization using signal-to-noise ratio $(\mathrm{S} / \mathrm{N})$ which is the logarithmic function of desired output to generate optimum design. The ratio depends on the output to be optimized. The response variable under study dictates the selection of $\mathrm{S} / \mathrm{N}$ ratio to be larger-the-better (LB), nominal-the-better (NB) or smaller-the-better (SB).

\section{Design of experiments}

The design of experiments is an important tool used in modeling and analyzing the influence of various factors involved in a process on the output. The output is termed as response variable or quality characteristic and the inputs are termed as process variables or factors.

Analysis of variance (ANOVA) was also performed to analyze the variance and the contribution of each factor to the response variables under study.

\section{Experimental}

The zirconia powder used was $8 \mathrm{~mol} \%$ Yttria Stabilized Zirconia (8YSZ) which is widely used as SOFC electrolyte (Tosoh, Japan). The YSZ powder was characterized by Scanning Electron Microscopy (SEM), Transmission Electron Microscopy (TEM), X-Ray Diffraction (XRD) and Particle Size Analysis. The XRD pattern was recorded using a Philips X-ray diffractometer with $\mathrm{CuK} \alpha$ as the radiation source and $\mathrm{Ni}$ as the filter. The average crystallite size values were estimated using the Scherrer equation [21]. The powder morphology was determined by using a SEM (Leo 4401). The particle size and shape were determined by using a TEM (JEOL-JEM 1000SX). The average agglomerated particle size of $8 \mathrm{YSZ}$ was measured using particle size analyzer (Sedigraph5100).

\section{Preparation of Ni-YSZ composite coating and its characterization}

Nickel sulfamate plating bath was prepared by mixing 300 g. $\mathrm{L}^{-1}$ of nickel sulfamate solution (50 g of Ni/L), $10 \mathrm{~g} . \mathrm{L}^{-1}$ of nickel chloride, $30 \mathrm{~g} . \mathrm{L}^{-1}$ boric acid and 0.2 g. $\mathrm{L}^{-1}$ of sodium lauryl sulfate. The Ni-sulfamate plating bath $(\sim 200 \mathrm{~mL})$ containing YSZ particle in a glass beaker was stirred using a magnetic stirrer at 
room temperature. The $\mathrm{pH}$ of the Ni-sulfamate bath was maintained at 4 by the addition of sulfamic acid and basic nickel carbonate. A pure nickel sheet $(2.5 \mathrm{~cm}$ $\mathrm{x} 12 \mathrm{~cm}$ ) and a brass substrate of the same dimension were used as anode and cathode, respectively. Polished brass substrates of area $2.5 \mathrm{~cm} \times 3.75 \mathrm{~cm}$ were degreased with acetone followed by cathodic cleaning and acid dipping and finally rinsed with distilled water. In order to ensure uniform dispersion of the powder, the electrolyte containing YSZ particles was subjected to magnetic stirring $(\sim 600 \mathrm{rpm})$ for 15 hours before the deposition process and during electrodeposition the particles were also magnetically stirred at $\sim 600 \mathrm{rpm}$. The electrodeposition was carried out on brass substrates at various current densities at room temperature by using an Aplab 7253 regulated DC power supply at various current densities.

The cross-sectional metallographic specimens were prepared by sandwiching electrodeposited Ni-YSZ brass coupons with a copper backup in a Bakelite matrix followed by mechanical grinding and polishing with $\mathrm{Al}_{2} \mathrm{O}_{3}$ slurry, down to $0.05 \mu \mathrm{m}$. The microhardness measurements were performed on ten different locations on the cross-section of each coating (Micromet 2103, Buehler, $50 \mathrm{gf}$ load). The optical micrographs of the cross sections of Ni-YSZ were recorded using Leica inverted metallurgical microscope (DMIRM). The area fraction of particles incorporated in the Ni matrix was calculated from the cross-sectional optical micrographs using image analysis software (Videopro 32 supplied by M/s Leading Edge, Australia) and the term area fraction is used throughout the text.

Table 1. Factors and the levels used for electrodeposition of Ni-YSZ composite coatings.

\begin{tabular}{|l|c|c|c|c|c|}
\hline S.No & Factor & Representation & Level 1 & Level 2 & Level 3 \\
\hline 1 & Concentration $\left(\mathrm{g} . \mathrm{L}^{-1}\right)$ & A & 20 & 60 & 100 \\
\hline 2 & Current density $\left(\mathrm{A} . \mathrm{dm}^{-2}\right)$ & B & 1.55 & 3.10 & 4.65 \\
\hline 3 & Time (hrs) & C & 3 & 1.5 & 1 \\
\hline
\end{tabular}

\section{Design factors}

Selection of process variables and their levels is a crucial exercise to be performed while designing the experiments. The properties of the Ni-composite coating developed depend on several factors. However, it has been found that the electrodeposition parameters like concentration of particles, applied current density and duration of experiment have the most influence on the coatings developed. In this paper we have studied the effect of three factors: applied current density, duration (time) of electrodeposition and YSZ particle concentration on the thickness, hardness and area fraction of the Ni-YSZ coatings. All the three factors were tested at three levels. The factors and their levels used for the electrodeposition of Ni-YSZ are tabulated in Table 1. Ideally we should use an array that contains three levels and three factors, i.e., $\mathrm{L}_{6}\left(3^{3}\right)$ orthogonal array. However, no such published array exists, then the next smallest array that will suit our problem is $\mathrm{L}_{9}\left(3^{4}\right)$ and hence an L9 array was selected for this study. Columns 1,2 and 3 were allocated to factors concentration, current 
density and time, respectively. The experimental layout is tabulated in Table 2. Nine experiments were conducted as per the L9 array.

Table 2. L9 experimental layout.

\begin{tabular}{|c|c|c|c|c|c|c|}
\hline \multirow{3}{*}{$\begin{array}{l}\text { Experiment } \\
\text { No } \\
1\end{array}$} & \multicolumn{6}{|c|}{ Column numbers and factor allocation } \\
\hline & \multicolumn{2}{|c|}{$\begin{array}{c}1 \\
\left.\text { Concentration (g.L }{ }^{-1}\right)\end{array}$} & \multicolumn{2}{|c|}{$\begin{array}{c}2 \\
\text { Current density }\left(\mathrm{A} . \mathrm{dm}^{-2}\right)\end{array}$} & \multicolumn{2}{|c|}{$\begin{array}{c}3 \\
\text { Time (hrs) }\end{array}$} \\
\hline & 20 & 1 & 1.55 & 1 & 3 & 1 \\
\hline 2 & 20 & 1 & 3.10 & 2 & 1.5 & 2 \\
\hline 3 & 20 & 1 & 4.65 & 3 & 1 & 3 \\
\hline 4 & 60 & 2 & 1.55 & 1 & 1.5 & 2 \\
\hline 5 & 60 & 2 & 3.10 & 2 & 1 & 3 \\
\hline 6 & 60 & 2 & 4.65 & 3 & 3 & 1 \\
\hline 7 & 100 & 3 & 1.55 & 1 & 1 & 3 \\
\hline 8 & 100 & 3 & 3.10 & 2 & 3 & 1 \\
\hline 9 & 100 & 3 & 4.65 & 3 & 1.5 & 2 \\
\hline
\end{tabular}

The response tables of mean $\mathrm{S} / \mathrm{N}$ ratio for thickness, microhardness and area fraction of Ni-YSZ composite coatings were calculated. The experimental responses obtained were subjected to regression models to obtain a linear fit relating the responses to the process variables. The predicted responses, the experimental responses and the residuals at each level of the three process variables were determined. The validity of the model and its independence of the observations were determined by performing ANOVA.

\section{Results and discussion}

The powder XRD pattern of 8YSZ showed peaks corresponding to zirconia cubic phase (JCPDS card no.27-997) (Fig. 1). The full width at half maxima (FWHM) of the peaks corresponding to (111), (200), (220), and (311) reflections of cubic zirconia were measured and the average crystallite size calculated from Scherrer equation was $18 \mathrm{~nm}$. The scanning electron micrograph (SEM) of 8YSZ is shown in Fig. 2.

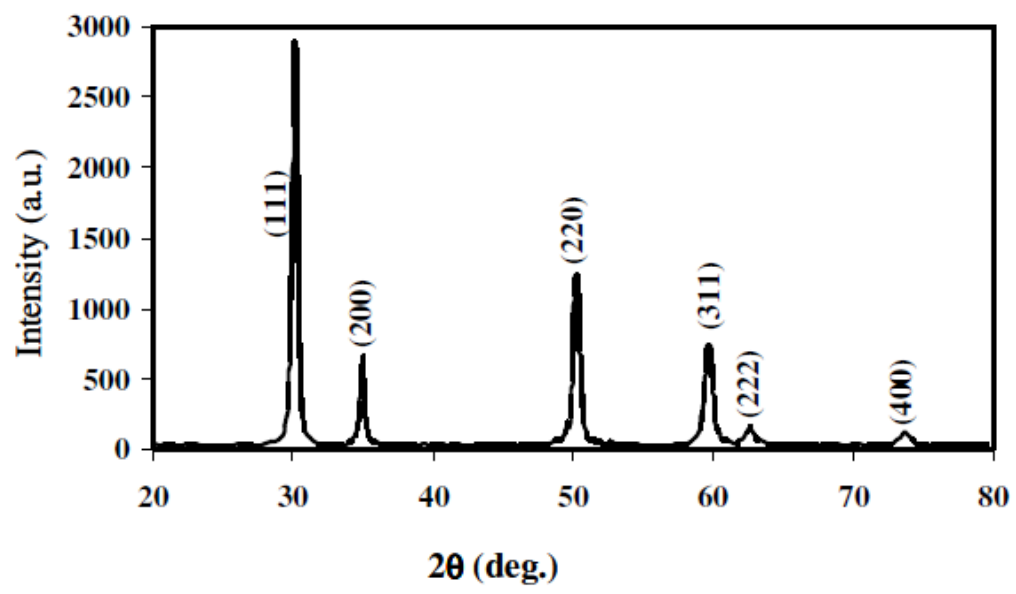

Figure 1. Powder XRD pattern of 8YSZ powder used for electrodeposition. 


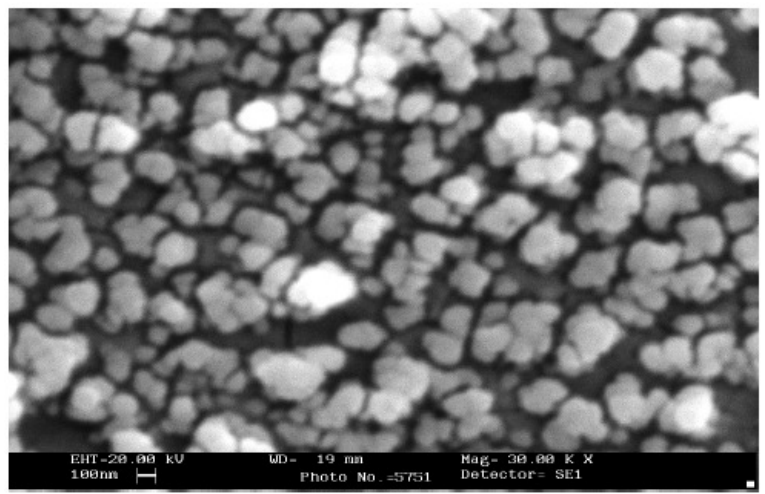

Figure 2. Scanning electron micrograph of 8 YSZ powder (Tosoh).

From the micrograph it is evident that the particles are seen as clusters and are almost spherical with particle size in the range of 50-200 $\mathrm{nm}$. The TEM also shows that the particles exist as agglomerates (Fig. 3). The particle size analysis showed a uniform distribution of particles with an average agglomerated particle size of $0.2 \mu \mathrm{m}$. The thickness of electrodeposited composite coatings was determined by the weight gained during electrodeposition. The optical micrograph of Ni-YSZ composite coatings clearly shows very good incorporation of particles in the nickel matrix (Fig. 4). Most of the particles were agglomerated.

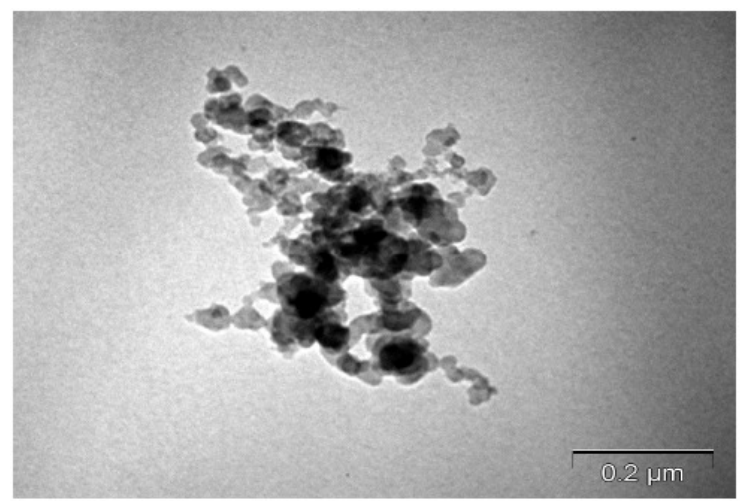

Figure 3. Transmission electron micrograph of 8 YSZ Tosoh powder.

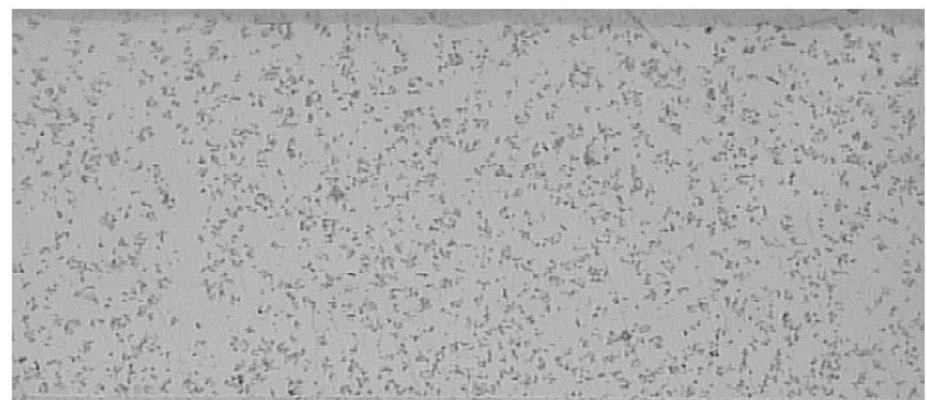

Figure 4. Cross-sectional optical micrograph of Ni-YSZ coating.

\section{Analysis of signal-to-noise ratio}

The optimum level of operation can be deduced by comparing the averages of the responses for each case. However, the variations due to factors cannot be accounted through average of the responses and hence signal-to-noise ratio 
method is used. The $\mathrm{S} / \mathrm{N}$ ratio is preferred to the traditional means as the former can capture variability within a trial condition. $\mathrm{S} / \mathrm{N}$ ratios were calculated for each experiment and averages were determined to obtain $\mathrm{S} / \mathrm{N}$ ratio for a given factor at a specific level. Since the aim of experiments was to enhance thickness, hardness and area fraction, we choose $\mathrm{S} / \mathrm{N}$ larger-the better and $\mathrm{S} / \mathrm{N}$ ratio was calculated using equation (1)

$$
\mathrm{S} / \mathrm{N}=-10 * \log \left((1 / n) \sum 1 / y^{2}\right)
$$

where $n$ represents the number of samples obtained from a given experiment and $y$ represents the output from the experiment. For example the $\mathrm{S} / \mathrm{N}$ ratio of factor A at Level 1 was calculated by averaging the $\mathrm{S} / \mathrm{N}$ ratio of experiments 1-3.

Table 3. Results of experiments.

\begin{tabular}{|l|l|l|l|l|l|l|}
\hline $\begin{array}{l}\text { Experiment } \\
\text { No }\end{array}$ & $\begin{array}{l}\text { Thickness } \\
(\boldsymbol{\mu m})\end{array}$ & $\begin{array}{l}\text { S/N } \\
\text { ratio }\end{array}$ & $\begin{array}{l}\text { Vickers } \\
\text { micro hardness } \\
(\mathbf{5 0} \text { gf })\end{array}$ & $\begin{array}{l}\text { S/N } \\
\text { ratio }\end{array}$ & $\begin{array}{l}\text { Area } \\
\text { fraction } \\
(\mathbf{\%})\end{array}$ & $\begin{array}{l}\text { S/N } \\
\text { ratio }\end{array}$ \\
\hline 1 & 61.6 & 35.79 & 411 & 52.27 & 9 & 19.08 \\
\hline 2 & 71.07 & 37.03 & 412 & 52.29 & 2.38 & 7.54 \\
\hline 3 & 58.85 & 35.39 & 378 & 51.54 & 3.48 & 10.83 \\
\hline 4 & 27.56 & 28.80 & 412 & 52.29 & 5.67 & 15.07 \\
\hline 5 & 31.88 & 30.07 & 410 & 52.25 & 6.26 & 15.94 \\
\hline 6 & 178.83 & 45.04 & 407 & 52.19 & 5.97 & 15.53 \\
\hline 7 & 19.77 & 25.92 & 380 & 51.59 & 10.19 & 20.58 \\
\hline 8 & 121.05 & 41.65 & 407 & 52.19 & 10.69 & 20.16 \\
\hline 9 & 87.85 & 38.87 & 446 & 52.98 & 12.25 & 21.76 \\
\hline
\end{tabular}

Table 4. Response table of mean $\mathrm{S} / \mathrm{N}$ ratio of thickness of Ni-YSZ composite coating.

\begin{tabular}{|l|c|c|c|c|}
\hline $\begin{array}{l}\text { Response } \\
\text { variable }\end{array}$ & \multicolumn{4}{|c|}{ Mean S/N ratio } \\
\hline \multirow{4}{*}{ Thickness } & Level & $\begin{array}{c}\text { Concentration } \\
\left(\mathbf{g . L}^{-1}\right)\end{array}$ & $\begin{array}{c}\text { Current density } \\
\left(\mathbf{A . d m}^{-2}\right)\end{array}$ & $\begin{array}{c}\text { Time } \\
(\mathbf{h r s})\end{array}$ \\
\cline { 2 - 5 } & 1 & 36.07 & 30.17 & 30.46 \\
\cline { 2 - 5 } & 2 & 34.64 & 36.25 & 34.90 \\
\cline { 2 - 5 } $\boldsymbol{\Delta}$ & 3 & 35.48 & 39.77 & 40.83 \\
\hline rank & & 1.43 & 9.60 & 10.37 \\
\hline
\end{tabular}

Table 5. Response table of mean S/N ratio for hardness of Ni-YSZ composite coating.

\begin{tabular}{|l|l|c|c|c|}
\hline Response variable & \multicolumn{4}{|c|}{ Mean S/N ratio } \\
\hline \multirow{3}{*}{ Microhardness } & Level & $\begin{array}{c}\text { Concentration } \\
\left(\mathbf{g . L}^{-\mathbf{1}}\right)\end{array}$ & $\begin{array}{c}\text { Current density } \\
\left(\mathbf{A . d m}^{-2}\right)\end{array}$ & $\begin{array}{c}\text { Time } \\
\text { (hrs) }\end{array}$ \\
\cline { 2 - 5 } & 1 & 52.04 & 52.05 & 52.22 \\
\cline { 2 - 5 } & 2 & 52.24 & 52.24 & 52.52 \\
\cline { 2 - 5 } $\boldsymbol{\Delta}$ & 3 & 52.26 & 52.24 & 51.80 \\
\hline rank & & 0.22 & 0.19 & 0.72 \\
\hline
\end{tabular}

Experimentally obtained thickness, microhardness and area fraction of particles are tabulated in Table 3 along with their corresponding S/N ratio. From Table 3 it is observed that the thickness ranges from about $20-179 \mu \mathrm{m}$ and the Vickers 
microhardness ranges from 378-450. The highest microhardness was exhibited by the composite electrodeposited at $4.65 \mathrm{~A} \cdot \mathrm{dm}^{-2}$ for $1.5 \mathrm{~h}$ and concentration of 100 g. $\mathrm{L}^{-1}$ of YSZ particles. The area fraction of particles incorporated was in the range of $2-13 \%$ as calculated from image analysis software.

Table 6. Response table of mean $\mathrm{S} / \mathrm{N}$ ratio for area fraction of Ni-YSZ composite coating.

\begin{tabular}{|l|c|c|c|c|}
\hline Response variable & \multicolumn{4}{|c|}{ S/N ratio } \\
\hline \multirow{3}{*}{ Area fraction } & Level & $\begin{array}{c}\text { Concentration } \\
\left(\mathbf{g . L}^{-1}\right)\end{array}$ & $\begin{array}{c}\text { Current } \\
\left(\mathbf{A . d m}^{-2}\right)\end{array}$ & $\begin{array}{c}\text { Time } \\
(\mathbf{h r s})\end{array}$ \\
\cline { 2 - 5 } & 1 & 12.48 & 18.22 & 15.75 \\
\cline { 2 - 5 } & 2 & 15.53 & 17.72 & 17.97 \\
\cline { 2 - 5 } & 3 & 20.83 & 16.03 & 26.78 \\
\hline $\boldsymbol{\Delta}$ & & 12.48 & 2.183 & 11.02 \\
\hline rank & & 1 & 3 & 2 \\
\hline
\end{tabular}

The results have been tabulated in Tables 4, 5 and 6 . These tables also contain delta which is the difference between the highest $\mathrm{S} / \mathrm{N}$ ratio and the lowest $\mathrm{S} / \mathrm{N}$ ratio. Ranks are assigned on the basis of the delta value; rank 1 is assigned to highest delta value, rank 2 is assigned to next highest value and so on.

In Table 4 of mean $\mathrm{S} / \mathrm{N}$ ratio of $\mathrm{Ni}$-YSZ composite coating thickness, the contribution from the particles was neglected as the delta value of concentration was significantly lower compared to that of current density and time. In Table 5 of mean $\mathrm{S} / \mathrm{N}$ ratio of $\mathrm{Ni}$-YSZ composite coating for microhardness, it was found that the change in time has the highest influence on hardness followed by change in concentration and then current density. From Table 6 for area fraction, it was found that the change in concentration has the highest influence followed by change in time and current density. Confirmatory tests corresponding to the optimum condition for $\mathrm{S} / \mathrm{N}$ ratio were performed: for area fraction the optimum conditions were $100 \mathrm{~g} . \mathrm{L}^{-1}, 1.55 \mathrm{~A} \mathrm{dm}^{-2}$ and $1 \mathrm{~h}$; for microhardness the optimum conditions were 100 g.L. $\mathrm{L}^{-1}, 4.56 \mathrm{~A} \mathrm{dm}^{-2}$ and for area fraction the optimum conditions were $100 \mathrm{~g} . \mathrm{L}^{-1}, 1.55 \mathrm{~A} \mathrm{dm}^{-2}$ and $1 \mathrm{~h}$. It is gratifying to note that a maximum microhardness of $526 \mathrm{HV}$, area fraction of $19 \%$ and thickness of 180 $\mu \mathrm{m}$ were obtained for the optimized $\mathrm{S} / \mathrm{N}$ ratio values. Accordingly there was an increase in the mean $\mathrm{S} / \mathrm{N}$ ratio (i) from 52.25 to 52.80 for microhardness; (ii) from 20.02 to 20.83 for area fraction and (iii) from 39.72 to 41.10 for thickness.

\section{Linear regression}

The responses obtained were subjected to regression to obtain a linear fit relating the responses to the process variables. The regression equation for thickness is represented by the following expression.

$$
\mathrm{Y}=\beta_{0}+\beta_{1} \mathrm{~b}+\beta_{2} \mathrm{~b}^{2}+\beta_{3} \mathrm{c}+\beta_{4} \mathrm{c}^{2}+\beta_{5} \mathrm{bc}
$$

It was found that concentration effect on the thickness was negligible and hence it was not included in the model. The regression equation for microhardness and area fraction is represented by the following expression: 


$$
Y=\beta_{0}+\beta_{1} a+\beta_{2} b+\beta_{3} c+\beta_{4} a b+\beta_{5} b c+\beta_{6} a c
$$

where $y$ is the response (hardness, thickness and area fraction), $\beta_{0}$ is a constant, $\beta_{1}, \beta_{2}, \beta_{3}, \beta_{4}, \beta_{5}, \beta_{6}$ are coefficients and $a$ represents absolute value of concentration used, $b$ represents absolute value of current density used and $c$ represents absolute value of time used. The coefficients have been tabulated in Table 7.

Table 7. Coefficients for responses.

\begin{tabular}{|l|c|c|c|c|c|c|c|}
\hline Response & $\boldsymbol{\beta}_{\mathbf{0}}$ & $\boldsymbol{\beta}_{\mathbf{1}}$ & $\boldsymbol{\beta}_{\mathbf{2}}$ & $\boldsymbol{\beta}_{\mathbf{3}}$ & $\boldsymbol{\beta}_{\mathbf{4}}$ & $\boldsymbol{\beta}_{\mathbf{5}}$ & $\boldsymbol{\beta}_{\mathbf{6}}$ \\
\hline Thickness $(\mu \mathrm{m})$ & -31.19 & 6.15 & -0.93 & 26.54 & -5.88 & 12.52 & - \\
\hline $\begin{array}{l}\text { Vickers micro } \\
\text { hardness }\end{array}$ & 572.6 & -2.07 & -42.82 & -35.17 & 0.57 & 5.00 & 0.18 \\
\hline Area fraction $(\%)$ & -18.57 & 0.23 & 3.78 & 9.35 & -0.01 & -1.59 & - \\
\hline
\end{tabular}

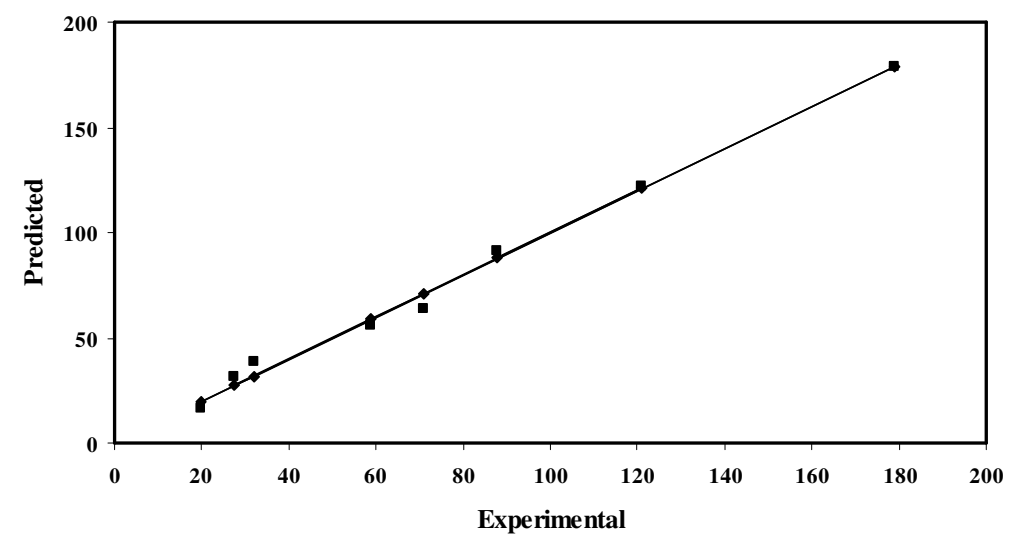

Figure 5. Predicted vs. experimental response of thickness.

It is evident that the regression equation for thickness is different and that of microhardness and area fraction are the same. This may be attributed to the fact that thickness of the deposit is mainly dependent on the current density and duration of plating. Higher the current density and duration of plating, higher will be the thickness of the coating. On the other hand, the microhardness of the coating and area fraction of particles present in the nickel matrix depend mainly on the amount of the particles present in the bath followed by current density and time. Higher the number of particles present in the bath, higher will be the amount of particle incorporation, higher will be the area fraction and higher will be the microhardness.

Fig. 5-10 show the predicted responses and the experimental responses and the residuals at each level of the three process variables. From these figures it is evident that for area fraction, predicted model is in good agreement with experimental values. The predicted models for thickness and hardness deviate at some experimental points but are in overall agreement. 


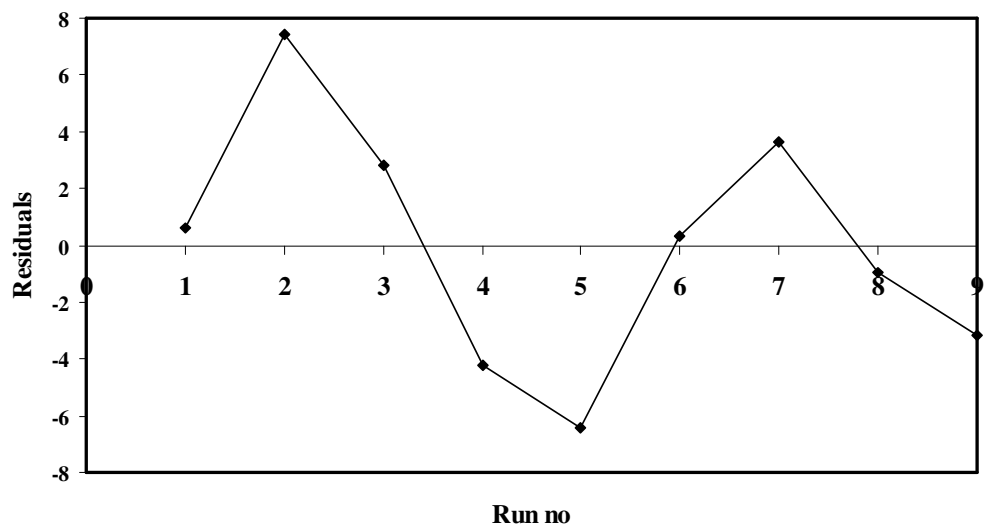

Figure 6. Residuals vs. run of thickness.

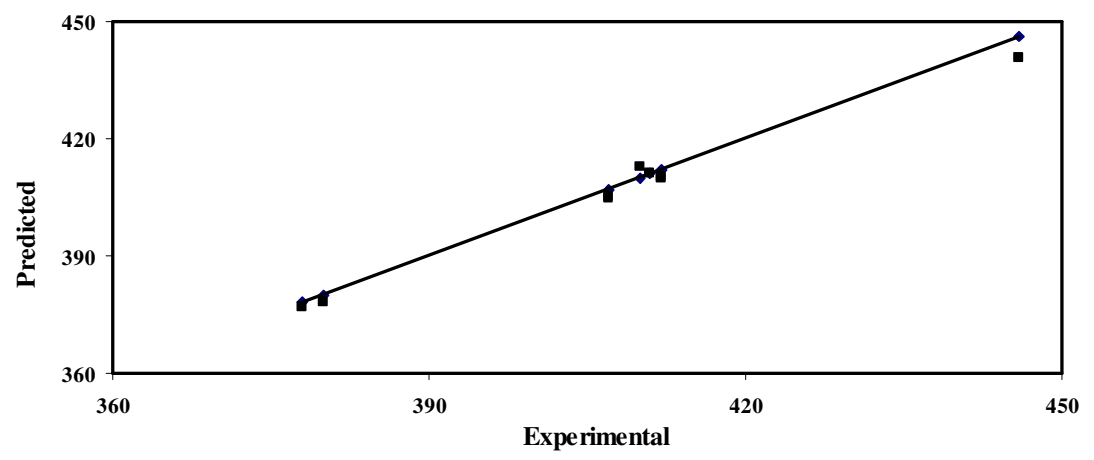

Figure 7. Predicted vs. experimental response of hardness.

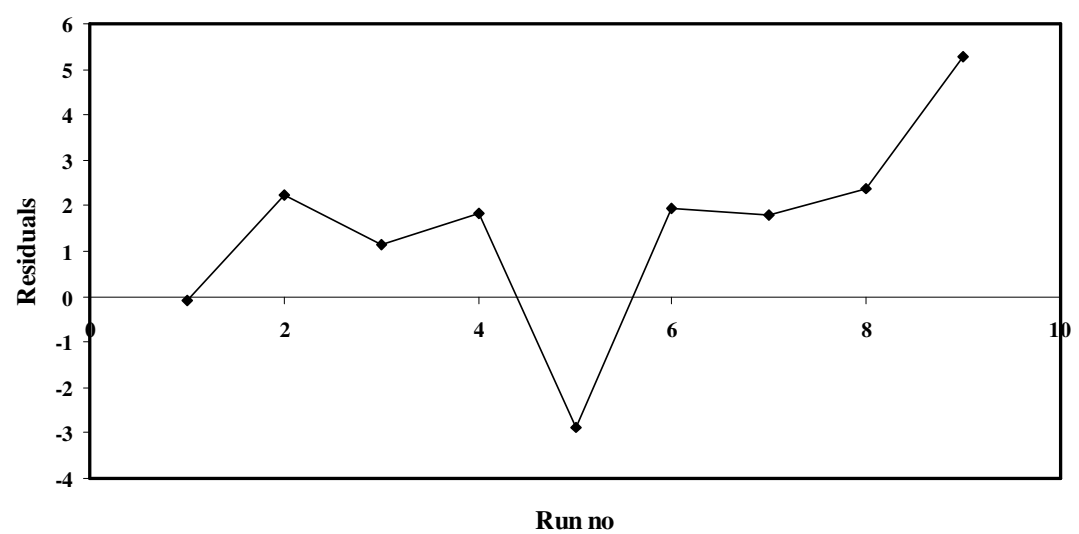

Figure 8. Residuals vs. run of hardness. 


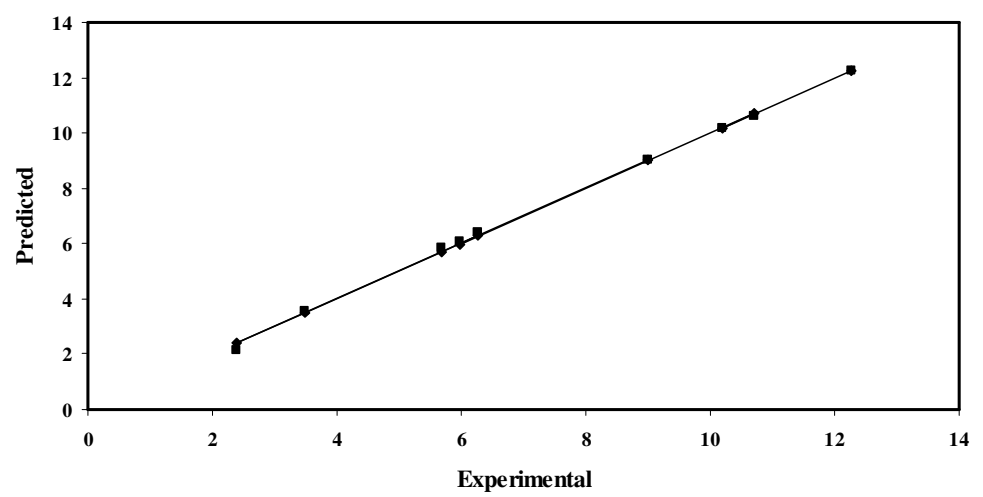

Figure 9. Predicted vs. experimental response of area fraction.

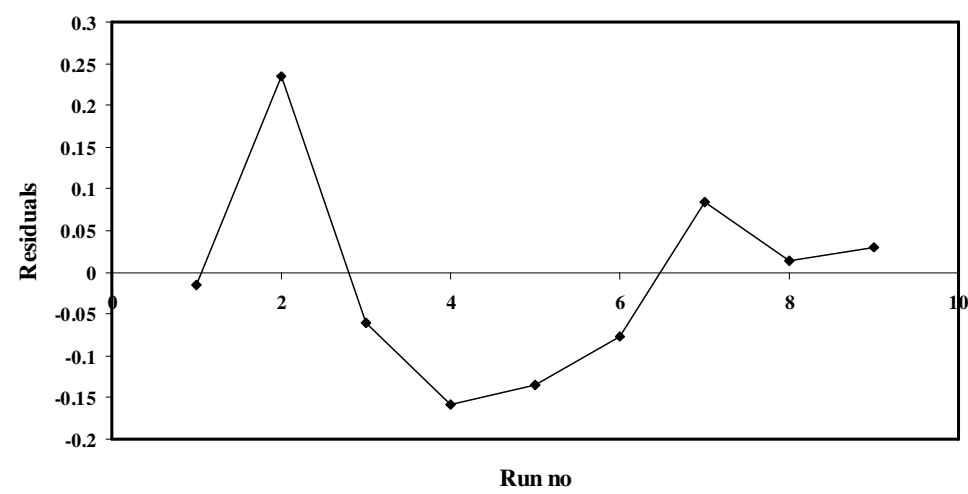

Figure 10. Residuals vs. run of area fraction.

\section{Analysis of variance (ANOVA)}

ANOVA was performed using Number Cruncher Statistical System (NCSS). It is an analysis software package which is available online for 7 days free trail. The ANOVA was performed on the three response variables and the results obtained have been tabulated in Tables $8-10$. The $\mathrm{R}^{2}$ value was close to 1 and the observed high F-ratios signify the validity of the model and its independence of the observations.

Table 8. ANOVA for thickness of Ni-YSZ composite coatings.

\begin{tabular}{|c|c|c|c|c|c|c|c|c|}
\hline Model term & DF & $\mathbf{R}^{2}$ & $\begin{array}{l}\text { Sum of } \\
\text { squares }\end{array}$ & $\begin{array}{c}\text { Mean } \\
\text { square }\end{array}$ & $\begin{array}{c}\text { F- } \\
\text { Ratio }\end{array}$ & $\begin{array}{l}\text { Prob } \\
\text { level }\end{array}$ & $\begin{array}{c}\text { Power } \\
(5 \%)\end{array}$ & $\begin{array}{c}\text { Contribution } \\
(\%)\end{array}$ \\
\hline Intercept & 1 & --- & 48174.4 & 48174.4 & --- & --- & --- & -- \\
\hline Model & 6 & 0.9929 & 20505.04 & 4101.008 & 83.679 & 0.002 & 1.000 & --- \\
\hline Current density & 1 & 0.0005 & 10.18571 & 10.18571 & 0.208 & 0.6794 & 0.0627 & 0.542883 \\
\hline Current density $^{2}$ & 1 & 0.0005 & 10.18509 & 10.18509 & 0.208 & 0.6795 & 0.0627 & 0.54285 \\
\hline Time & 1 & 0.0020 & 40.51728 & 40.51728 & 0.827 & 0.4303 & 0.1007 & 2.15951 \\
\hline Time $^{2}$ & 1 & 0.0017 & 35.93133 & 35.93133 & 0.733 & 0.4548 & 0.0949 & 1.915085 \\
\hline $\begin{array}{l}\text { Current } \\
\text { density*Time }\end{array}$ & 1 & 0.0790 & 1632.381 & 1632.381 & 33.308 & 0.0103 & 0.9564 & 87.00343 \\
\hline Error & 2 & 0.0071 & 147.0258 & 49.00861 & -- & --- & --- & 7.836252 \\
\hline Total (Adjusted) & 8 & 1.0000 & 20652.06 & 2581.50 & --- & --- & --- & --- \\
\hline
\end{tabular}

$\mathrm{DF}=$ Degrees of freedom 
Table 9. ANOVA for microhardness of Ni-YSZ composite coatings.

\begin{tabular}{|l|c|c|c|c|c|c|c|c|}
\hline Model term & DF & $\mathbf{R}^{\mathbf{2}}$ & $\begin{array}{c}\text { Sum of } \\
\text { squares }\end{array}$ & $\begin{array}{c}\text { Mean } \\
\text { square }\end{array}$ & $\begin{array}{c}\text { F- } \\
\text { Ratio }\end{array}$ & $\begin{array}{c}\text { Prob } \\
\text { level }\end{array}$ & $\begin{array}{c}\text { Power } \\
(\mathbf{5 \%})\end{array}$ & $\begin{array}{c}\text { Contribution } \\
(\mathbf{\%})\end{array}$ \\
\hline Intercept & 1 & & $\begin{array}{c}149084 \\
1\end{array}$ & $\begin{array}{c}149084 \\
1\end{array}$ & --- & --- & --- & --- \\
\hline Model & 6 & 0.9917 & 3139.78 & 523.29 & 39.91 & 0.0246 & 0.875 & --- \\
\hline Concentration & 1 & 0.3337 & 1056.44 & 1056.44 & 80.58 & 0.012 & 0.981 & 22.3 \\
\hline Current density & 1 & 0.2843 & 900.23 & 900.23 & 68.67 & 0.014 & 0.966 & 19.0 \\
\hline Time & 1 & 0.0927 & 293.48 & 293.48 & 22.38 & 0.041 & 0.681 & 6.2 \\
\hline $\begin{array}{l}\text { Concentration*Curren } \\
\text { t density }\end{array}$ & 1 & 0.6930 & 2194.18 & 2194.18 & $\begin{array}{c}167.3 \\
7\end{array}$ & 0.0059 & 0.999 & 46.4 \\
\hline Current density*Time & 1 & 0.0394 & 124.81 & 124.81 & 9.52 & 0.0909 & 0.402 & 2.60 \\
\hline Concentration*Time & 1 & 0.0453 & 143.37 & 143.37 & 10.93 & 0.08 & 0.442 & 3.0 \\
\hline Error & 2 & 0.0083 & 26.21 & 13.10 & --- & --- & --- & 0.2 \\
\hline Total (adjusted) & 8 & 1.0000 & 3166 & 395.75 & --- & --- & --- & -- \\
\hline
\end{tabular}

From the tables, it was observed that the $\mathrm{R}^{2}$ value was close to 1 in all the cases and F-ratio for thickness and area fraction were higher, which signifies the aptness of the model chosen. Factor effects with a significance level of 0.05 or lower (probability level $\leq 0.05$; confidence level $-95 \%$ ) show that the factor effects are significant.

Table 10. ANOVA for area fraction of Ni-YSZ composite coatings.

\begin{tabular}{|l|c|c|c|c|c|c|c|c|}
\hline Model term & DF & $\mathbf{R}^{\mathbf{2}}$ & $\begin{array}{c}\text { Sum of } \\
\text { squares }\end{array}$ & $\begin{array}{c}\text { Mean } \\
\text { square }\end{array}$ & $\begin{array}{c}\mathbf{F}- \\
\text { Ratio }\end{array}$ & $\begin{array}{c}\text { Prob } \\
\text { level }\end{array}$ & $\begin{array}{c}\text { Power } \\
(\mathbf{5 \%})\end{array}$ & $\begin{array}{c}\text { Contribution } \\
(\boldsymbol{\%})\end{array}$ \\
\hline Intercept & 1 & & 482.93 & 482.93 & --- & --- & --- & --- \\
\hline Model & 6 & 0.9987 & 91.47 & 15.24 & 264.19 & 0.001 & 1.00 & --- \\
\hline Concentration & 1 & 0.1496 & 13.70 & 13.70 & 237.44 & 0.002 & 1.00 & 20 \\
\hline Current density & 1 & 0.0766 & 7.01 & 7.01 & 121.59 & 0.001 & 0.99 & 10 \\
\hline Time & 1 & 0.2266 & 20.75 & 20.75 & 359.60 & 0.001 & 1.00 & 30 \\
\hline Concentration*Current & 1 & 0.0085 & 0.78 & 0.78 & 13.52 & 0.062 & 0.50 & 2 \\
\hline Current density*Time & 1 & 0.1597 & 14.62 & 14.62 & 253.46 & 0.001 & 1.00 & 21 \\
\hline Concentration*Time & 1 & 0.1244 & 11.39 & 11.39 & 197.51 & 0.001 & 0.99 & 17 \\
\hline Error & 2 & 0.0013 & 0.11 & 0.05 & --- & --- & --- & 0 \\
\hline Total (adjusted) & 8 & 1.0000 & 91.58 & 11.44 & --- & --- & --- & --- \\
\hline
\end{tabular}

Table 8 shows that the interaction of current density and time has the highest influence on the thickness of the coating formed followed by time. $\mathrm{R}^{2}$ value of 0.9929 and F-ratio of 83.67 suggest the aptness of the predicted model. Table 9 shows that the interaction of current density and concentration has the highest influence followed by concentration and current density. $\mathrm{R}^{2}$ value of 0.9917 and F-ratio of 39.91 suggest the aptness of the predicted model. From Table 10, it is evident that the significant factors contributing to the thickness of the coatings are time, followed by interaction of current and time and concentration. $\mathrm{R}^{2}$ value of 0.9987 and F-ratio of 264.19 suggest the correctness of the model, being considerably higher when compared to those of micro hardness and thickness, as shown in Tables 8 and 9. The $\mathrm{R}^{2}$ values predicted for the three responses were close to 1 , indicating excellent agreement within predicted and experimental values, based on which it can be concluded that model follows a linear fit with the above considered process variables and their subsequent combinations. 
Table 11. Confirmatory experiments conducted with results and error \%.

\begin{tabular}{|l|c|c|c|c|c|}
\hline S.No & $\begin{array}{c}\text { Experimental } \\
\text { conditions } \\
\text { (concentration; current } \\
\text { density; time) }\end{array}$ & $\begin{array}{c}\text { Response } \\
\text { variable }\end{array}$ & Predicted & Experimental & $\begin{array}{c}\text { Error } \\
(\%)\end{array}$ \\
\hline 1 & C:A:C & $\begin{array}{c}\text { Area fraction } \\
(\%)\end{array}$ & 10.552 & 10.627 & 7.10 \\
\hline 2 & C:B:B & $\begin{array}{c}\text { Micro hardness } \\
(\text { Vickers,50gf) }\end{array}$ & 407 & 374 & 8.21 \\
\hline 3 & C:C:B & $\begin{array}{c}\text { Thickness } \\
(\mu m)\end{array}$ & 54.32 & 49.81 & 8.33 \\
\hline
\end{tabular}

Table 11 shows the confirmatory experiments performed and the deviations from the predicted results along with the error \%. Fig. 11 shows the dependence of area fraction on the interaction of current density and time.

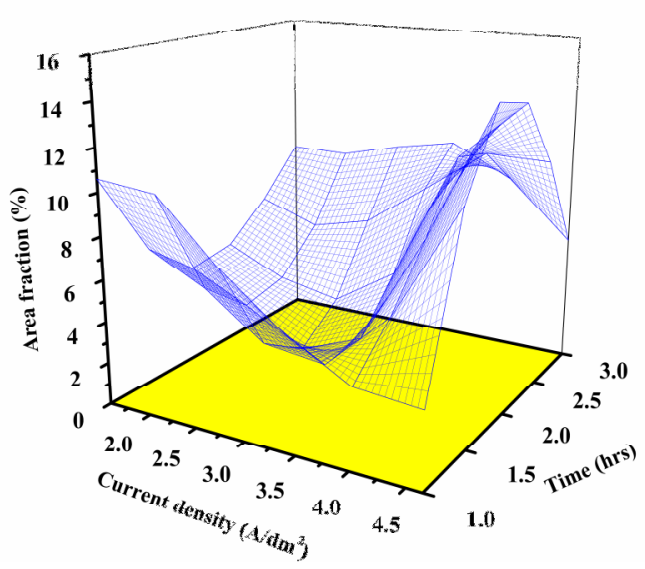

Figure 11. Dependence of area fraction of particles incorporated on the interaction of current density and time.

\section{Conclusions}

An orthogonal L9 array study was performed on the response parameters thickness, microhardness and area fraction of the electrodeposited Ni-YSZ composite coatings. The levels of operation for high gain in performance of each response were identified using analysis of $\mathrm{S} / \mathrm{N}$ ratios. Confirmatory tests corresponding to the optimum condition for $\mathrm{S} / \mathrm{N}$ ratio were performed for area fraction, microhardness and thickness. It is gratifying to note that a maximum microhardness of $526 \mathrm{HV}$, area fraction of $19 \%$ and thickness of $180 \mu \mathrm{m}$ were obtained for the optimized $\mathrm{S} / \mathrm{N}$ ratio values. Accordingly, there was an increase in the mean $\mathrm{S} / \mathrm{N}$ ratio for all the responses. Linear fit regression models were also obtained for each response. According to the experimental results and ANOVA, the interaction of current and time are the most significant factors influencing the thickness of the coating; interaction of concentration of particles and current density are the most significant factors influencing the microhardness; and time is the most significant factor affecting the area fraction of particles in the $\mathrm{Ni}$ matrix. ANOVA was performed on each model and aptness of each model was 
verified using the $\mathrm{R}^{2}$ value which was found to be close to 1 in all the three cases. The confirmatory experiments were performed to verify the predicted models and the experimental results were found to be close to the predicted values within $8 \%$ error range.

\section{Acknowledgements}

The authors thank Director, NAL for the encouragement and permission to publish this work.

\section{References}

1. A. Hovestad, L.J.J. Janssen, J. Applied Electrochem. 25 (1995) 519-527. 10.1007/BF00573209

2. V.P. Greco, Electrocomposites, AESF press, USA, 1987. pp. 7-8.

3. H. Zhao, L. Liu, J. Zhu, Y. Tang, W. Hu, Mater. Lett. 61 (2007) 1605-1608. 10.1016/j.matlet.2006.07.178

4. A.M. El-Sherik, U. Erb, J. Mater. Sci. 30 (1995) 5743-5749. 10.1007/BF00356715

5. L. Benea, P.L. Bonora, A. Borello, S. Martelli, Mater. Corros. 53 (2002) 23-29. 10.1002/1521-4176(200201)53:1<23::AID-MACO23>3.0.CO;2-0

6. P. Gyftou, M. Stroumbouli, E.A. Pavlatou, P. Asimidis, N. Spyrellis, Electrochim. Acta 50 (2005) 4544-4550. 10.1016/j.electacta.2004.10.090

7. F. Hou, W. Wang, H. Guo, App. Surf. Sci. 252 (2006) 3812-3817. 10.1016/j.apsusc.2005.05.076

8. A. Moller, H. Hahn, Nanostructured Mater. 12 (1999) 259-262. 10.1016/S0965-9773(99)00112-9

9. B. Szczygiel, M. Kolodziej, Electrochim. Acta 50 (2005) 4188-4195. 10.1016/j.electacta.2005.01.040

10. J. Li, J. Jiang, H. He, Y. Sun, J. Mater. Sci. Lett. 21 (2002) 939-941. 10.1023/A:1016073606681

11. Y-J. Xue, J.-S. Li, W. Ma, M.-D. Duan, J. Mater. Sci. 41 (2006) 1781-1784. 10.1007/s10853-006-3947-2

12. N.S. Qu, D. Zhu, K.C. Chan, Scripta Mater. 54 (2006) 1421-1425. 10.1016/j.scriptamat.2005.10.069

13. S.T. Aruna, C.N. Bindu, V. Ezhil Selvi, V.K. William Grips, K.S. Rajam, Surf. Coat. Tech. 200 (2006) 6871-6880. 10.1016/j.surfcoat.2005.10.035

14. J.B. Wachtman, Mechanical properties of ceramics, New York: Wiley; 1996. p. 173.

15. S-L. Kuo, J. Chin. Inst. Eng. 27 (2004) 243-251.

16. K. Ramanathan, V.M. Periasamy, U. Natarajan, Port. Electrochim Acta 26 (2008) 361-368. 10.4152/pea.200804361

17. P. Sahoo, S.K. Pal, Tribol. Lett. 28 (2007) 191-201. 10.1007/s11249-0079264-3

18. W.L. Liu, S.H. Hseih, W.J. Chen, J.H. Lee, Surf. Coat. Technol. 201 (2007) 9238-9242. 10.1016/j.surfcoat.2007.04.064 
19. R.A.C. Santana, A.R.N. Campos, E.A. Medeiros, A.L.M. Oliveira, L.M.F. Silva, S. Prasad, J. Mater. Sci. 42 (2007) 9137-9144. 10.1007/s10853-0071931-0

20. Taguchi's Quality Engineering Handbook. G. Taguchi, S. Chowdhury, Y. Wu, John Wiley \& Sons, Inc., New York, 2005.

21. H. Klug, L.Alexander, in "X-ray Diffraction Procedures for polycrystalline and amorphous materials", John Wiley, New York, 1974. pp. 618, 708. 